\title{
Le monde du travail au Japon à travers \\ "Stupeur et tremblements" \\ d'Amélie Nothomb
}

\author{
Manal Zahran \\ Maître de conférences - Faculté de pédagogie \\ Université Ain-Chams - Département de français
}

\begin{abstract}
:
Née en 1967 à Kobe,au Japon, Amélie Nothomb est fille de l'ambassadeur de Belgique à Rome.Après avoir terminé ses études de philologie romane à l'université libre de Bruxelles, Nothomb a décidé de retourner au Japon son pays natal où elle a passé ses cinq premières années espérant trouver un avenir radieux.

Embauchée dans une grande entreprise japonaise, puisqu'elle maîtrise plus que trois langues, la jeune belge est passée par tous les stades de l'humiliation morale et physique qui reflètent le système rigide qui domine le monde du travail japonais.Dans Stupeur et Tremblements, Amèlie Nothomb explore son expérience poignante marquée par la souffrance et l'affliction qu'elle a subies durant son stage pratique au Japon.Dans cette optique notre étude portera sur deux points essentiels:

1-Le calvaire enduré par l'étrangère lors de son travail au Japon.

2-Les différents procédés auxquels la jeune romancière a eu recours pour pouvoir franchir les humiliations et les persécutions infligées par ses supérieurs.
\end{abstract}

\section{Introduction:}

Dans Stupeur et tremblements, Amélie Nothomb ${ }^{(1)}$ explore, à travers son expérience traumatisante et ses souvenirs épouvantables dans une grande entreprise japonaise, l'implacable rigueur qui gouverne le monde du travail au Japon.

Après avoir terminé ses études de philologie romane à l'université libre de Bruxelles, Amélie Nothomb a décidé de retourner au Japon son pays natal où elle a passé ses cinq premières années espérant mener une vie stable après tant de voyages avec ses parents, et trouver un brillant avenir dans un pays civilisé et développé comme le pays du Soleil-Levant.

Embauchée dans une prestigieuse firme japonaise, puisqu'elle parle couramment le japonais,Nothomb est passée par tous les stades de l'humiliation morale et physique qui reflètent l'intransigeance,l'intolérance et encore le racisme dissimulés sous le masque de la civilisation et le progrès technique d'un énorme pays comme le Japon.Cette expérience affligeante, riche en péripéties, a ébranlé la jeune romancière et l'a encouragée à la relater à travers ce roman autobiographique.

Selon Luk Fui Lee dans Michel Tournier et le détournement de l'autobiographie:"Le but de l'autobiographie est de suivre la trace des événements passés d'un individu.Cependant la vie humaine n'est pas statique:chaque jour, chaque minute, chaque seconde apportent des transformations insignifiantes ou dramatiques(...).Comme une coquille vide,l'autobiographie ne laisse que la trace d'une vie antérieure et passée, et ne peut donner qu'une image partielle et extérieure 
de moi qui se transforme continuellement et se définit par la création."(Fui Lee, 2003:39).

Dans cette optique notre étude portera sur deux points essentiels:

1-Le calvaire enduré par l'étrangère pendant son travail dans une grande compagnie japonaise.

2- Les différents procédés auxquels la jeune belge a eu recours pour franchir les humiliations et les persécutions infligées par ses supérieurs.

Pour mieux comprendre les procédés auxquels Nothomb a eu recours pour surmonter les défis et les tourments infligés par ses supérieurs,il nous a paru utile d'incorporer les théories de la psychanalyse et les mécanismes de défense qui ont aidé la jeune romancière à endurer le calvaire d'un an dans le pays du Soleil-Levant.

1-Le calvaire enduré par l'étrangère pendant son travail dans une grande compagnie japonaise.

L'année atroce que la jeune romancière a passée au sein de la firme japonaise n'était qu'une suite de rudes épreuves ininterrompues.Le régime rigoureux du travail au Japon avec toutes ses formes les plus draconiennes trouve son plein épanouissement à travers l'expérience déplorable et pénible que Nothomb nous raconte dans Stupeur et tremblements.

Rien n'est plus expressif que le titre du roman Stupeur et tremblements. De prime abord on remarque l'absence d'article qui "tend à transformer un nom abstrait en allégorie. Dans la description et l'énumération, elle renforce la signification $d u$ nom tout en raccourcissant le rythme de la phrase."(Yves, 1995:34).

Cette définition éloquente accentue l'énumération et l'omniprésence des situations qui provoquent la stupeur et les tremblements de la jeune romancière pendant son stage pratique dans la grande compagnie japonaise Yumimoto où elle a souffert le martyre durant un an.

Quant au choix de ce titre, il remonte à un ancien protocole impérial nippon où " il est stipulé que l'on s'adressera à l'Empéreur avec" Stupeur et tremblements » (Nothomb,1999:160) .

Influencée par la culture japonaise, la jeune belge se trouvait obligée de manifester la stupeur qui signifie l'étonnement profond de tout ce qui est bizarre et incompréhensible pour elle. Cette stupéfaction qui nécessite et exige une explication ou une justification pour tout ce qui l'entoure,signifie, selon la tradition japonaise, "l'infériorité $d u$ cerveau occidental par rapport au cerveau nippon. »(Nothomb, 1999:157).

Cette Stupeur doit être accompagnée de tremblements qui marquent la crainte, la faiblesse, l'infériorité, l'humiliation et la soumission absolue sans le moindre mouvement de résistance.

Malgré la stupeur et les tremblements que la jeune belge manifestait devant ses supérieurs afin de les satisfaire et de gagner leur confiance, elle n'a réussi ni à trouver une place dans la firme japonaise Yumimoto ni à s'intégrer à la société japonaise. Stupeur et tremblements «raconte une tentative d'intégration sociale et raciale ratée, en l'occurrence la mienne. Au Japon, persuadée d'être japonaise, j'ai tenté de m'intégrer par le biais du travail dans une énorme entreprise et ce fut un désastre. »(Jaccomard,2004:14).Dès le début du roman, la nouvelle stagiaire nous 
indique la place subalterne qu'elle a occupée dans la grande entreprise et qui affirme le système implacable du travail qui prend les allures du racisme dont elle a profondément souffert dès son arrivée à la firme japonaise .

"Monsieur Haneda était le supérieur de monsieur Omochi, qui était le supérieur de monsieur Saito, qui était le supérieur de mademoiselle Mori, qui était ma supérieure. Et moi, je n'étais la supérieure de personne. [...]. Donc, dans la compagnie Yumimoto, j'étais aux ordres de tout le monde. »(Nothomb,1999:7).Ce premier paragraphe du roman révèle un système hiérarchique implacable et intransigeant qui broie l'individu, quelle que soit sa compétence, au profit du travail. Cette hiérarchie rigoureusement réglée et strictement pratiquée, interdit à une occidentale hébétée d'occuper une place supérieure et lui permet à peine d'avoir une place à sa base.

Cette place abjecte au pied de la pyramide dans l'entreprise japonaise était un présage qui a permis à la nouvelle stagiaire de comprendre qu'elle est une intruse complètement refusée par tout son entourage que ce soit le cadre spatial ou les personnages comme elle nous révèle " [...] je fus engagée dans une grande entreprise japonaise. Ce fut épouvantable et celle-là m'a fait comprendre que ma carrière japonaise était une voie de garage. Si je la prolongeais, je devais accepter d'être malheureuse toute ma vie. »(Amanieux,2005:80).

\section{I- Le cadre Spatial :}

le cadre spatial a joué un rôle de première importance pour nous transmettre que la jeune occidentale était dévalorisée et méprisée même par les objets-lieux et les objets inertes qui l'entourent.

A ce propos, Laureline Amanieux nous révèle «L'espace, peu décrit dans les romans de Nothomb, est cependant éminemment symbolique : il est la projection des violences mentales et physiques que se font subir les personnages. »(Amanieux,2005:159).

Dès son arrivée à la grande compagnie japonaise, la nouvelle venue,réprouvée par tout son entourage, nous transmet l'attitude hostile et répugnante des objets inertes à son égard.Rien n'est plus expressif que la personnification des objets-lieux qui ont mal accueilli la nouvelle venue. "L'ascenseur me cracha au dernier étage de l'immeuble Yumimoto. La fenêtre, au bout du hall, m'aspira comme l'eût fait le hublot brisé d'un avion. Loin, très loin, il y avait la ville - si loin que je doutais d'y avoir jamais mis les pieds. »(Nothomb,1999:7-8) . Même l'ascenseur, cet appareil clos qui sert à transporter verticalement des personnes aux différents étages d'un immeuble, ne supporte pas l'existence de la nouvelle venue et la rejette au quarante quatrième étage de ce gratte-ciel comme si elle était une épidémie ou un microbe dont on doit se méfier ou se débarrasser. L'ascenceur repousse l'intruse pour que la fenêtre l'attire vers le vide qu'elle a profondément admiré à travers la baie vitrée comme elle nous révèle "En vérité, il n'y avait dans ma tête aucune pensée, rien que la fascination pour le vide, par la baie vitrée. »(Nothomb,1999:8). Ce vide était, à la fois, à l'intérieur et à l'extérieur de l'entreprise.Éructée par l'ascenseur, la nouvelle occidentale se trouvait toute seule dans le vide d'un immense hall. Personne ne lui accorde le moindre intérêt. Comme elle était au dernier étage de ce gratte-ciel, la nouvelle venue ne voyait à travers la baie vitrée que le vide devant elle qui signifie qu'elle était complètement éloignée et exclue de tout le monde. Rien 
n'est plus frappant que l'attitude passive de la nouvelle stagiaire à l'égard de tout ce qui lui arrive. Comme elle est étrangère, Amélie se laisse mener par les circonstances sans manifester aucune résistance au point de nous donner l'impression qu'elle est une personne vulnérable et sans volonté et qu'elle ne peut avoir le moindre contrôle sur tout ce qui lui arrive.

II-Les personnages .A-Monsieur Saito . Indifférente aux réglements du système du travail,la nouvelle venue,sans préjudice d'éventuelles poursuites, est montée au dernier étage de l'immeuble sans penser à se présenter à la réception. « Je ne songeai même pas qu'il ê̂t fallu me présenter à la réception. " (Nothomb, 1999:8).

Cette première erreur commise par la nouvelle stagiaire occidentale a excité l'indignation et la colère de monsieur Saito le permier personnage ou plutôt le premier bourreau qui a surpris la

jeune occidentale en train de contempler le vide à travers la baie vitrée «Une voix rauque finit par prononcer mon nom, derrière moi. Je me retournai. Un homme d'une cinquantaine d'année, petit, maigre et laid, me regardait avec mécontentement.

Pourquoi n'avez-vous pas averti la réceptionniste de votre arrivée? me demanda-t-il ?»(Nothomb,1999:8).. Frappée par l'apparition subite de monsieur Saito, la jeune occidentale est restée paralysée et incapable de répondre à ses questions. «Je ne trouvai rien à répondre et ne répondis rien. J'inclinai la tête et les épaules, constatant qu'en une dizaine de minutes, [...], j'avais déjà produit une mauvaise impression, le jour de mon entrée dans la compagnie Yumimoto. »(Nothomb,1999:8). Agacé par l'attitude répréhensible de la nouvelle stagiaire occidentale et submergé d'un désir ardent de l'humilier, monsieur Saito ne s'est même pas donné la peine de lui préciser la nature de son travail dans l'entreprise. Après avoir présenté la jeune belge à ses supérieurs et à ses collègues, monsieur Saito lui a confié d'écrire une lettre à son ami pour l'inviter à jouer au golf avec lui le dimanche suivant. Cette tâche explicitement facile et simple n'était pas un travail autant qu'un défi qui vise à mépriser les aptitudes de la jeune occidentale et à lui prouver qu'elle est incompétente et ne mérite pas l'honneur de travailler dans une entreprise japonaise.

Sans parvenir à comprendre l'intention vindicative de monsieur Saito, la jeune européenne s'est mise à rédiger la lettre avec enthousiasme croyant que c'est une tâche très facile et simple à effectuer. "L'exercice me parut facile. Je m'assis et écrivis une lettre cordiale :monsieur Saito se réjouissait à l'idée de jouer au golf le dimanche suivant avec monsieur Johnson et lui envoyait ses amitiés. »(Nothomb,1999:10) .

Cette première tentative de la part de la jeune occidentale était inadmissible et frustrée par monsieur Saito qui a déchiré la lettre et l'a forcée à l'écrire de nouveau. «Monsieur Saito lut mon travail, poussa un petit cri méprisant et le déchira: . Recommencez. »(Nothomb,1999:10)

Sans oser demander une explication pour cette répétition inutile, la jeune belge s'est mise à répéter acharnement son travail tout en essayant de chercher une nouvelle formule pour la rédaction de la lettre. Sans le moindre commentaire et sans 
préciser la faute de la nouvelle stagiaire, monsieur Saito a rejeté la lettre pour la deuxième

fois par le même cri méprisant et l'a obligée à la recommencer. Soumise aux ordres de son supérieur, la nouvelle stagiaire a passé des heures à répéter la rédaction de la lettre sans relâche et sans plainte en s'efforçant à chaque fois d'inventer une formulation nouvelle qui peut satisfaire monsieur Saito mais en vain.

«Je passai les heures qui suivirent à rédiger des missives à ce joueur de golf. Monsieur Saito rythmait ma production en la déchirant, sans autre commentaire que ce cri qui devait être un refrain. »(Nothomb,1999:11).

Ce travail futile et absurde est interrompu par l'arrivée de mademoiselle Mori la supérieure directe de la nouvelle stagiaire.

Après cette première tâche répétitive sans profit, la jeune belge est restée au chômage des jours et des jours espérant comprendre exactement sa profession ou son rôle dans cette gigantesque entreprise. Frustrée par ce commencement attristant, la jeune belge n'arrivait pas à croire qu'elle a quitté son pays et elle a mis toute cette distance entre la Belgique et le Japon pour répéter un travail infructueux.

Marginalisée par tout son entourage, la nouvelle stagiaire sentait qu'elle n'avait aucune compétence dont on peut profiter dans cette colossale entreprise. Ce sentiment amer a produit chez elle une mauvaise impression qu'elle nous traduit ainsi: "Les employés de Yumimoto comme les zéros, ne prenaient leur valeur que derrière les autres chiffres. Tous, sauf moi, qui n'atteignais même pas le pouvoir du zéro. Les jours s'écoulaient et je ne servais toujours à rien.[...]. J'avais l'impression que l'on m'avait oubliée, [...]. » (Nothomb,1999:16). Passés les jours fastidieux et monotones,.monsieur Saito a décidé d'infliger à la nouvelle stagiaire une autre tâche plus humble que la précédente. Cette tâche consiste à préparer ce qu'on appelle selon la tradition japonaise «l'ôchakumi » ou bien «La fonction de l'honorable thé. »(Nothomb,1999:17) Cette nouvelle tâche qui paraît très simple incarne le racisme au vrai sens du terme. D'une part elle impose à la jeune occidentale la tradition japonaise et l'oblige à la respecter malgré elle,d'autre part, elle représente une sorte d'humiliation qui vise à mépriser et à dévaloriser une polyglotte qui maîtrise plus que trois langues et digne d'être une interprète simultanée dans une prestigieuse firme comme Yumimoto. "Cette humble tâche se révéla le premier instrument de ma perte. »(Nothomb,1999:17).

Cependant, la jeune belge s'est ingéniée à accomplir ce modeste travail à la perfection comme s'il était un travail d'une importance considérable. «Je pris ce rôle d'autant plus au sérieux que c'était le seul qui m'était dévolu. [...]. S'il existait un ordre du mérite de l'ôchakumi, il ê̂t dû m'être décerné. »(Nothomb,1999:17).

Malheureusement, cette tâche, soigneusement effectuée par la jeune européenne n'a provoqué que son malheur et sa déception. Ignorant les règlements stricts et rigoureux qui interdisent à une étrangère blanche de parler la langue japonaise devant les partenaires, la jeune occidentale a servi l'honorable thé devant la délégation d'une firme amie avec des formules qui affirment qu'elle maîtrise la langue japonaise ce qui a excité l'anxiété des membres du groupe ainsi que la fureur de ses supérieurs. Au comble de l'irritation, monsieur Saito, explique à la jeune belge la dimension de sa faute impardonnable et l'étendue du désastre "Vous avez profondément indisposé la délégation de la firme amie! [...]. Vous avez créé 
une ambiance exécrable dans la réunion de ce matin: comment nos partenaires auraient-ils pu se sentir en confiance,avec une Blanche qui comprenait leur langue? A partir de maintenant, vous ne parlez plus japonais.[...]. Il y a toujours moyen d'obéir. C'est ce que les cerveaux occidentaux devraient comprendre. »(Nothomb,1999:19-20).

Malgré l'effort que la jeune belge a déployé pour accomplir parfaitement son travail et malgré son insistance à satisfaire son supérieur, la pauvre était toujours désappointée, humiliée et reprimandée. Personne n'estime ses qualités, ses compétences et ses efforts même dans les tâches les plus subalternes. Toute tentative d'efficacité et de dévouement de sa part est considérée comme une affirmation de sa supériorité occidentale et par conséquent elle était rencontrée par des réprobations navrantes. La tâche de présenter le thé honorable dans la compagnie japonaise n'était pas la dernière, mais elle était accompagnée d'une nouvelle mission plus insignifiante et plus futile, c'est celle de mettre les calendriers à jour.

Rongée par l'ennui et dévorée par le désespoir de trouver un travail qui va de pair avec ses compétences linguistiques, la jeune belge ne trouvait aucun problème cette fois-ci de demander à monsieur Saito la permission de se charger de mettre les calendriers de chaque bureau dans l'entreprise à jour. Convaincu que la jeune stagiaire ne méritait que les tâches anodines, monsieur Saito, raciste et xénophobe lui a permis sans hésitation de lui confier cette besogne rebutante comme d'habitude pour renforcer sa place au bas de l'échelon hiérarchique de la grande entreprise «Il (M.Saito) me répondit oui sans y prendre garde. Je considérai que j'avais un métier.[...]. J'avais un poste: j'étais avanceuse - tourneuse de calendriers. »(Nothomb,1999:29).

Ce modeste travail, parfaitement accompli par la jeune belge a provoqué les éclats de rire des employés qui n'arrivent pas à s'empêcher de se moquer d'elle et de sa besogne inutile «Peu à peu, les membres de Yumimoto s'aperçurent de mon manège. Ils en conçurent une hilarité grandissante. On me demandait :-Ça va? Vous ne vous fatiguez pas trop à cet épuisant exercice?(Nothomb, 1999:29) .

L'apparition de la jeune occidentale chaque jour dans les bureaux des employés pour ajuster les calendriers était tellement ridicule qu'elle provoque une explosion de rires de tout le monde comme si « elle faisait le pitre ».(Nothomb,1999:30).

Cette hilarité générale qui était étrange et même anormale dans une entreprise où règne une ambiance rigoureuse, sérieuse et stricte qui interdit toute marque de légèreté ou de souplesse ont excité la colère de monsieur Saito qui l'a accusée d'avoir dérangé les employés et de les avoir empêchés de se concentrer. «[...]; vous déconcentrez les employés. »(Nothomb,1999:31).

Gêné par l'atmopshère joviale que la jeune occidentale a créée par son travail comique, monsieur Saito qui s'ingéniait à l'humilier en lui confiant des tâches de plus en plus dégradantes et avilissantes, a décidé de l'affliger d'une nouvelle besogne abjecte et non productive comme châtiment pour son crime d'avoir perturbé le système du travail en avançant les calendriers. La nouvelle mission accordée à la jeune belge consiste à photocopier une énorme liasse de pages mille copies. Croyant que cette mission est très facile et n'exige aucun effort, la pauvre occidentale a livré le paquet à l'avaleuse de la photocopieuse qui a terminé la tâche avec une rapidité et une perfection extrêmes. 
Cependant, monsieur Saito, visant toujours à tourmenter la jeune occidentale, a désapprouvé ses photocopies sous pretexte qu'elles sont décentrées et l'a obligée à recommencer le travail sans utiliser l'avaleuse prétendant qu'elle n'est pas précise. L'intransigeance de monsieur Saito a excité la stupeur et la curiosité de la jeune occidentale qui n'arrive pas à comprendre et lui demande une explication ainsi : «Monsieur Saito, sans l'avaleuse, il me faudrait des heures pour en venir à bout .

-Où est le problème? sourit-il. Vous manquiez justement d'occupation. »(Nothomb, 1999:32).

Cette réponse bourrue a réussi à transmettre le message à sa destinataire. «Je compris que c'était mon châtiment pour l'affaire des calendriers. »(Nothomb,1999:33).

Saisi par des sentiments hostiles à l'égard de la jeune occidentale, monsieur Saito a continué à la torturer en la forçant à répéter la photocopie des pages une par une plusieurs fois et à réprimer toutes ses tentatives de perfectionner son travail. "Vous êtes en progrès, mais ce n'est pas encore la perfection. Recommencez. Et il jeta la liasse à la poubelle. » (Nothomb,1999:39).

Raciste aveugle, monsieur Saito n'a pas hésité à abîmer Amélie dans l'affliction en lui attribuant des missions inutiles et sans valeur comme pour lui prouver que les occidentaux ne méritent que ces travaux anodins et subalternes qui correspondent à leurs mentalités débiles.

\section{B-Fubuki Mori}

Le deuxième personnage ou plutôt le deuxième tortionnaire qui a persécuté la jeune occidentale,c'est mademoiselle Fubuki Mori la supérieure directe de la jeune occidentale. Comme elle représente le seul personnage féminin qui figure dans le roman à part la jeune belge, Fubuki reflète un autre aspect plus dur et plus cruel de la vie professionnelle au sein de la société japonaise. C'est la misogynie.

Choquée par les préceptes de la culture japonaise, Nothomb dénonce, dans une dizaine de pages, la condition lamentable et la position pénible de la femme japonaise cachées sous le masque

de la civilisation et du progrès.C'est incroyable et même inimaginable qu'un pays civilisé et avancé aussi que le pays du Soleil-Levant dévalorise et humilie la femme en lui imposant un lourd fardeau de préjugés et d'idées saugrenues capable de la broyer et de l'anéantir.

Fascinée par la lutte de la femme japonaise et sa résistance à l'assaut des contraintes de sa société, Nothomb l'apprécie et fait d'elle une héroïne vaillante capable d'affronter " tant de corsets physiques et mentaux, tant de contraintes, d'écrasements, d'interdits absurdes, de dogmes, d'asphyxie, de désolations, de sadisme, de conspiration du silence et d'humiliations. »(Nothomb,1999:87).

La jeune européenne glorifie la persévérance de la femme japonaise et la considère comme «un miracle d'hérö̈sme ».(Nothomb,1999:87). et un peu plus loin elle affirme que «S'il faut admirer la japonaise - et il le faut -, c'est parce qu'elle ne se suicide pas. On conspire contre son idéal depuis sa plus tendre enfance. On lui coule du plâtre à l'intérieur du cerveau. »(Nothomb,1999:87) .

Émue par la situation inique de la femme japonaise qui apitoie les cœurs les plus endurcis, la jeune occidentale n'a pas manqué de nous dévoiler les préceptes de la société japonaise qui écrasent et oppriment la femme sur tous les plans pour nous 
faire compatir à sa souffrance et à sa douleur.«Si à vingt-cinq ans tu n'es pas mariée, tu auras de bonnes raisons d'avoir honte ». [...]. "Si ton visage exprime un sentiment, tu es vulgaire ", " si tu mentionnes l'existence d'un poil sur ton corps, tu es immonde, " "si un garçon t'embrasse sur la joue en public, tu es une putain", " si tu manges avec plaisir, tu es une truie », "si tu éprouves du plaisir à dormir, tu es une vache. " etc... »(Nothomb,1999:87-88).

Notons aussi que la culture japonaise élève ces préceptes oppressifs au rang de devoir suprême dont le but essentiel est de contraindre la femme «à être irréprochable. »(Nothomb,1999:89). Autrement dit ces devoirs exigent de la femme qu'elle atteigne une perfection extrême. «Être irréprochable ne te rapportera rien d'autre que d'être irréprochable, ce qui n'est ni une fierté ni encore moins une volupté. »(Nothomb, 1999:89).

Frappée de stupeur et d'ahurissement, la jeune belge énumère les devoirs et les charges accablantes qui pèsent sur tous les moments essentiels de la vie de la femme japonaise. «Mange à peine, car tu dois rester mince [...], parce qu'il est honteux d'avoir des rondeurs. Tu as pour devoir d'être belle [...]. Tu as pour devoir

de te marier, de préférence avant tes vingt-cinq ans qui seront ta date de péremption. [...]. Tu as pour devoir d'avoir des enfants [...]. Ton devoir est de te sacrifier pour autrui. [...]. »(Nothomb,1999:90-91). La liste infinie de ces devoirs éprouvantes dépasse les limites du possible pour atteindre le moindre détail de la vie de la femme japonaise même dans les domaines les plus intimes et les plus nécessaires comme son humble besoin d'aller à la salle de bain. " [...] même quand tu seras isolée aux toilettes [...] tu auras l'obligation de veiller à ce que personne ne puisse entendre la chansonnette de ton ruisseau : tu devras donc tirer la chasse sans trêve. »(Nothomb, 1999:89).

À cette liste sans bornes la jeune belge ajoute un autre devoir surprenant et excentrique qui contraint la femme japonaise à éviter autant que possible tout ce qui provoque la transpiration car «il n'y a pas plus honteux que la sueur. »(Nothomb,1999:94).

C'est plus honorable de se suicider que de transpirer «Entre le suicide et la transpiration n'hésite pas. Verser son sang est aussi admirable que verser sa sueur est innommable. »(Nothomb,1999:95) Toutes ces contraintes et ces blocages des mentalités affirment que la culture japonaise misogyne ôte à la femme tous ses droits même les plus nécessaires et les plus impérieux et en même temps elle l'accable d'une lourde liste de devoirs affligeants et iniques .

La misogynie atteint son paroxysme par l'inégalité flagrante et injuste des sorts de l'homme et de la femme que la jeune belge n'a pas manqué de nous révéler «Mais le Nippon, lui, n'est pas un asphyxié. On n'a pas détruit en lui, dès son plus jeune âge, toute trace d'idéal. Il possède l'un des droits humains les plus fondamentaux : celui de rêver, d'espérer. »(Nothomb, 1999:95).

Cette iniquité évidente apparaît par excellence dans le domaine du travail. « Espérer travailler. Il y a peu de chances. »(Nothomb,1999:88).

La culture japonaise dévalorise les capacités de la femme et ne respecte jamais son droit de se réaliser dans une carrière et d'avoir un avenir radieux et par conséquent elle restreint ses ambitions et réduit ses occasions de travail dans tous les domaines. 
L'entreprise Yumimoto où la jeune belge travaillait, représente un bon témoignage de la discrimination inique entre l'homme et la femme. Dans cet édifice la présence de la femme est tellement restreinte qu'elle ne peut jamais dépasser les cinq pour cent «Dans la compagnie, pour une centaine d'hommes, il devait y avoir cinq femmes. »(Nothomb, 1999:128).

Fubuki Mori la supérieure directe de la jeune belge dans la compagnie japonaise représente l'une des victimes qui a tant souffert de ce lourd fardeau de contraintes et de défis intolérables imposés à la femme japonaise.

La culture japonaise, avec ses conceptions et ses traditions préjudiciables cachées sous la couche brillante et éblouissante de la civilisation et du progrès, a prêté à Fubuki la cruauté et l'intransigeance dissimulées sous sa beauté captivante qui a fasciné la jeune occidentale dès la première rencontre. Munie d'un pinceau d'un peintre doué, la jeune belge décrit la beauté physique de Fubuki Mori "Mademoiselle Mori mesurait au moins un mètre quatre vingts, [...]. Elle était svelte et gracieuse à ravir, le spectacle de son visage était captivant [...]. Elle avait le plus beau nez du monde [..]. Son teint à la fois blanc et mat était celui dont parle si bien Tanizaki. Fubuki incarnait à la perfection la beauté nippone. »(Nothomb, 1999:13-14).

Cependant les charmes accaparants de Fubuki n'étaient pas une raison suffisante pour lui offrir la chance de se marier « Si tu es une belle fille, tu ne seras pas grand-chose; si tu n'es pas une belle fille, tu seras moins que rien. »(Nothomb,1999:90). Absorbée jusqu'au bout par son travail laborieux, Fubuki, malgré sa beauté exceptionnelle, a dépassé l'âge de vingt-cinq ans, date de péremption, sans se marier. Malheureusement le système harassant de son travail dévore tout son temps au point de la priver de rencontrer une personne convenable ou de vivre une aventure amoureuse. Son emploi du temps était si encombré qu'il ne lui permettait pas de fonder un foyer et d'avoir un mari et des enfants « Depuis sept ans, elle avait englouti son existence entière dans le travail. Avec fruit, puisqu'elle avait effectué une ascension professionnelle rare pour un être du sexe féminin. »(Nothomb,1999:97).

Désespérée de s'affranchir de son état de célibataire mal jugé par la société,Fubuki, accablée de son statut honteux comme femme non mariée, a découvert que son travail est la seule chose qui lui reste et qui peut combler les lacunes de sa vie. Motivée par un désir obsessionnel de se réaliser dans sa carrière,Fubuki,s'obstine à travailler d'arrache-pied, à lutter, à déployer un effort considérable, à surmonter des obstacles infranchissables et à affronter courageusement des défis intolérables "Mademoiselle Mori a souffert des années pour obtenir le poste qu'elle a aujourd'hui. »(Nothomb,1999:49).

Le calvaire que Fubuki a enduré tant d'années dans son travail pour arriver à un poste prestigieux ainsi que les contraintes qu'elle a affrontées de la part de la société à cause de son célibat prolongé ,l'ont rendue cruelle, dure, intransigeante et parfois sadique. «Son visage l'apparentait à «l'œillet du vieux Japon » symbole de la noble fille du temps jadis : posé sur cette silhouette immense, il était destiné à dominer le monde. »(Nothomb,1999:15) Fubuki incarne le racisme au vrai sens du terme, elle est comme Nothomb la surnomme «ma tortionnaire. »(Nothomb,1999:101) En principe « le raciste est celui qui s'affirme. Il déteste la différence de l'autre. Jamais 
il ne cherchera à comprendre comment peut vivre son voisin, ce qu'il peut aimer, ce qu'il peut penser, ce qu'il peut sentir. Il s'en moque. ».(Amanieux,2005:85).

Tel était le cas de Fubuki avec la jeune occidentale. Au début de leur connaissance, la jeune belge avoue qu'il y avait une affection cordiale et une amitié indéfectible qui la liaient avec sa supérieure directe et qui l'aidaient à supporter le temps qui passait avec lenteur,avec lourdeur et sans profit. «j'étais enchantée de ma collègue. Son amitié me paraissait une raison plus que suffisante pour passer dix heures par jour au sein de la compagnie Yumimoto. »(Nothomb,1999:14).

Convaincue que la jeune stagiaire est une occidentale mal accueillie et indésirable dans la compagnie et qu'elle ne peut jamais occuper un poste remarquable ou être une rivale dangereuse pour elle, Fubuki était la seule personne qui la traitait cordialement et qui la consolait de la méchanceté de monsieur Saito.Malheureusement, les beaux moments sont toujours très courts, cette bonne relation entre la jeune belge et sa belle supérieure n'a pas duré longtemps.

Ayant découvert que monsieur Tenshi, le directeur de la section des produits laitiers, a accordé à la jeune occidentale la chance de se réaliser et de prouver ses compétences en lui confiant une tâche respectable qui peut bouleverser complètement son destin , Fubuki, jalouse et égoïste, a décidé de se venger d'elle afin d'étouffer ses ambitions et de détruire ses rêves.

La tâche que monsieur Tenshi a confiée à la jeune belge consiste à rédiger un rapport complet sur un nouveau procédé d'allégement du beurre produit par une entreprise belge. Comme monsieur Saitama, l'employé qui devait accomplir ce travail, ne parlait pas le français et ne connaissait pas la Belgique, en outre il était en voyage d'affaires, monsieur Tenshi, craignant que le nouveau beurre allégé soit convoité par d'autre pays avant la rentrée de monsieur Saitama, a eu recours à la jeune belge qui possède la langue française.

La jeune occidentale, qui attendait avec impatience la chance de s'affirmer et de se réaliser dans l'entreprise à travers un poste qui convient à ses compétences et qui remplace les tâches subalternes et inutiles dont elle a tant souffert, a accompli cette mission à la perfection et avec une rapidité formidable qui a extrêmement étonné monsieur Tenshi qui l'a remerciée infinement et lui a promis de suggérer à ses supérieurs la possibilité de travailler avec lui. Ce succès brillant a complètement troublé la relation qui liait la jeune stagiaire avec sa supérieure Fubuki. Le sentiment d'amitié que Fubuki éprouvait à l'égard d'Amélie s'est transformé, tout d'un coup, en hostilité, en jalousie et en rancune. Comme la jeune occidentale a exécuté parfaitement le travail qui lui a été confié par monsieur Tenshi sans demander la permission de sa supérieure, Fubuki, afin de réprimer la recrue, a exploité cette faute indéfendable et n'a pas hésité un instant à dénoncer monsieur Tenshi et sa partenaire chez le vice-président monsieur Omochi. Ayant appris que Fubuki est la personne qui l'a dénoncée, Amélie, déçue et saisie par un état de fureur indescriptible dû « au coup de massue »(Nothomb,1999:48), qu'elle a reçu, a insisté à affronter sa supérieure afin de lui reprocher sa trahison incompréhensible et de lui demander une explication logique et raisonnable pour son attitude répréhensible.

Comme son nom signifie « tempête de neige »(Nothomb,1999:24), Fubuki, avec la froideur de la neige avoue franchement et sans honte sa trahison à la jeune belge sans manifester le moindre signe de regret ou de remords à son égard. "Vous avez 
brigué une promotion à laquelle vous n'aviez aucun droit, déclare Fubuki à la jeune belge, [...] J'ai vingt-neuf ans, vous en avez vingt-deux. J'occupe mon poste depuis l'an passé. Je me suis battue pendant des années pour l'avoir. Et vous, vous imaginez que vous allez obtenir un grade équivalent en quelques semaines? [...]. Moi [...] je n'avais pas d'estime pour vous. »(Nothomb,1999:52-53).

Cette confrontation acerbe et brutale entre la jeune stagiaire et sa supérieure a déclenché la guerre entre les deux, et le rêve de la jeune occidentale de se réaliser dans une brillante carrière s'est vaporisé.

Profitant de son autorité comme supérieure directe, Fubuki a commencé à infliger à la jeune belge des tâches qui vont à l'encontre de ses compétences comme interprète qui maîtrise plusieurs langues et pour lesquelles elle était engagée dans la grande firme.

La nouvelle affectation que Fubuki a assigné à la jeune occidentale consiste à classer les factures, à recopier dans chaque colonne, la date, le nom de la compagnie et le montant et enfin à les ranger dans un grand tiroir. Comme elle nous évoque : "Il n'y avait pas tant de différence entre le métier de moine copiste, au Moyen âge et le mien, je passais des journées entières à recopier des lettres et des chiffres. »(Nothomb,1999:56).

Malheureusement les factures étaient si nombreuses que la jeune belge a commis de graves bévues et une confusion indescriptible des lettres et des chiffres qui dépassent l'entendement. Ces fautes grossières dues à l'ignorance crasse et au manque d'expérience de la jeune stagiaire ont excité les éclats de rire et les moqueries de tous les employés de la section comptabilité et ont attisé la colère terrible de sa supérieure Fubuki. «Fubuki, elle ne riait toujours pas. Son visage exprimait la plus terrifiante des colères contenues. Si elle avait pu me gifler, elle l'eut fait. »(Nothomb,1999:59) .

En proie à une grande contrariété,Fubuki,convaincue que la jeune belge a commis ces erreurs colossales exprès pour se venger d'elle, lui a fait des reproches véhéments. "Vous vous conduisez aussi bassement que les autres occidentaux. [...].Pour vous venger de mon attitude envers vous, vous n'avez pas hésité à saboter la comptabilité de Yumimoto, sachant pertinement que vos torts retomberaient sur moi. [...]. Je n'ignore pas que vous êtes peu intelligente, cependant, personne ne pourrait être assez stupide pour faire de pareilles fautes [...]. Vous trouvez honorable d'affirmer sans vergogne que vous êtes la dernière des imbéciles. [...].(Nothomb, 1999:63-64).

Avec un ton ironique,Fubuki, lui lance en pleine figure - «Si vous apparteniez à la catégorie des handicapés mentaux, il fallait me le dire, au lieu de me laisser vous confier cette tâche. »(Nothomb,1999:64).

Cette rude épreuve qui a affligé la jeune occidentale n'était pas la dernière. De plus en plus, son destin s'assombrit par la belle tortionnaire Fubuki qui, afin de régler ses comptes avec elle, insistait à lui attribuer une nouvelle affectation encore liée au domaine de la comptabilité qui n'intéresse pas du tout la jeune occidentale. «commença alors l'un des pires cauchemars de ma vie, déclare la jeune belge. Dès l'instant où cette nouvelle tâche me fut attribuée, la notion de temps disparut de mon existence pour laisser place à l'éternité du supplice. »(Nothomb,1999:66) 
Bien qu'elle sache que la jeune stagiaire souffre d'un manque d'expérience et d'une maladresse concernant la comptabilité, Fubuki, exploitant la lacune de la novice, refuse impitoyablement et avec un sourire narquois ses excuses et insiste à lui infliger ce labeur sous pretexte qu'il est facile et qu'il n'exige pas beaucoup de temps, tout en lui expliquant sur sa calculette les étapes qu'elle doit suivre pour effectuer rapidement les opérations.

Comme le temps s'écoulait sans le moindre progrès, la jeune débutante, errante et incapable de sortir du labyrinthe des chiffres, a décidé de passer les trois dernières nuits qui précèdent la date de l'échéance au sein de la compagnie Yumimoto, espérant trouver une issue de cette impasse .

Après avoir passé trois nuits blanches au milieu des chiffres et des nombres, la jeune apprentie insomniaque,dévorée par un désespoir insondable,ne trouve autre solution que d'annoncer lamentablement son échec et sa défaite devant sa supérieure. «Vous avez raison :C'est au-dessus de mes capacités, je vous l'annonce solennellement : Je renonce à cette tâche. »(Nothomb,1999:81)

Fubuki qui attendait impatiemment la défaillance d'Amélie, n'a pas manqué de guetter l'occasion pour lui affirmer que son impuissance remonte, incontestablement, à l'hébétude de la mentalité occidentale en se moquant d'elle ainsi «Il s'agit pourtant d'un travail qui sollicite l'intelligence, repliqua-t-elle, implacable. »(Nothomb,1999:67) .

Afin de lui démontrer le génie de la mentalité japonaise, Fubuki, satisfaite de l'embarras, de l'humiliation et de la honte indélébile de la jeune belge devant elle, a achevé fièrement le travail, que la jeune occidentale a passé des semaines sans pouvoir terminer, à une vitesse fulgurante qui ne dépasse pas vingt minutes.

La foudroyante chute de la jeune occidentale au fond de l'abîme n'avait pas de frein. La rancune que Fubuki éprouve à l'égard d'Amélie atteint son paroxysme par la nouvelle et ultime affectation qu'elle lui a infligée et qui représente une surprise et un choc à la fois pour le lecteur autant que pour la jeune stagiaire. Ce nouveau poste est : nettoyeuse de chiottes.

En effet, ce nouveau supplice était une sorte de châtiment pour la jeune occidentale qui a osé poursuivre sa supérieure aux toilettes afin de la consoler et de l'amadouer après l'interminable agression verbale qu' elle a subie du vice - président qui l'a bassement humiliée devant la quarantaine de membres de la section comptabilité. Touchée par ce spectacle abominable et dégradant en public, la jeune stagiaire, motivée par sa bonté d'âme, a décidé de rejoindre sa supérieure afin d'apaiser sa douleur après les insultes et les humilitations du vice-président monsieur Omochi. «Fubuki, je suis désolée! je suis de tout cœur avec vous, je suis avec vous. »(Nothomb,1999:116).

Malheureusement, la belle supérieure japonaise, influencée par la philosophie des Samouraïs avec «ses valeurs de sacrifice, de discipline, de fidélité absolue envers les supérieurs. »(Amanieux,2005:47), a considéré la pitié et la compassion que la jeune belge a manifestées à son égard une sorte de vengeance, voire un crime qui mérite d'être condamné. Selon la philosophie des Samouraïs «le combattant se devait de ne jamais montrer de marques de souffrance, d'endurer les épreuves avec une force et une tenue hors du commun, et d'avoir vaincu en lui la peur de la mort. »(Amanieux,2005:47). 
Tel était le cas de Fubuki la belle supérieure japonaise. Après avoir perdu la face devant tous ses collègues par les offenses et les vigoureuses attaques du vice président, Fubuki, stoïque et forte, a réussi, à peine, à dominer sa colère et à cacher sa souffrance et ses larmes devant tout le monde en abandonnant précipitamment la

place pour aller se réfugier dans les toilettes. Cependant la jeune occidentale, imprudemment, a eu la hardiesse de briser l'isolement de sa supérieure dans les toilettes comme si elle insistait à la vexer en la regardant sangloter dans un état de faiblesse et de souffrance déplorable.Avec une vive anxiété, la jeune belge traduit la colère de Fubuki à l'égard de son attitude exaspérante. "Au paroxysme de la haine, [...]. Fubuki marcha vers moi, avec Hiroshima dans l'œil droit et Nagasaki dans l'oil gauche.[...]. Si elle avait eu le droit de me tuer, elle n'eût pas hésité." (Nothomb,1999:117) .

Avec une méchanceté constante qui prend des allures de haine et de vengeance, Fubuki n'a trouvé autre châtiment plus humiliant et plus vil que le nettoyage des toilettes. Rien n'est plus expressif que l'ironie avec laquelle la belle supérieure explique à la jeune belge son nouveau poste supposant que même cette méprisable tâche sera incompréhensible pour elle et au-dessus de ses aptitudes occidentales abruties. «Le visage assuré, Fubuki me montra, très professionnelle, les gestes qui seraient désormais les miens. Il s'agissait de remplacer le rouleau de "tissu sec et propre " [...] ; il s'agissait aussi de renouveler les fournitures de papier-toilette au sein de cabinets - [...]. Le clou fut atteint quand la belle créature empoigna délicatement la brosse à chiottes pour m'expliquer, avec beaucoup de sérieux quel en était le mode d'emploi. »(Nothomb,1999:120-121).

Pour jouir de la souffrance de la jeune occidentale dans ce poste humiliant,Fubuki tâche d'aller aux toilettes plusieurs fois par jour sous pretexte de brosser ses dents. "Fubuki semblait plus enragée que jamais de se rendre aux commodités. Elle entreprit même d'aller s'y brosser les dents deux fois par jour.[...]. Elle m'en voulait tant de ne pas avoir démissionné que tous les prétextes lui étaient bons pour venir me narguer. »(Nothomb,1999:133-134). Bref, Fubuki, la belle créature, s'est efforcée d'engouffrer la jeune belge au fond d'un puits insondable dont il est difficile de sortir.

\section{C-Monsieur Omochi}

Le troisième bourreau qui a également participé à la mortification et à la dévalorisation de la jeune occidentale c'est le vice-président monsieur Omochi qui représente par excellence la méchanceté, la grossièreté et l'agressivité.

Pour mieux comprendre le comportement agressif et sadique de monsieur Omochi, on a eu recours à la psychanalyse qui définit l'agressivité ainsi : «tendance ou ensemble de tendances qui s'actualisent dans des conduites réelles ou fantasmatiques, celles-ci visant à nuire à autrui, le détruire, le contraindre, l'humilier, etc. »(Laplanche,1967:13) .

Quant au sadique, «il jouit de la souffrance et de la douleur qu'il impose aux autres, comme il jouit de celle qui lui est ou fut infligée, mais à laquelle il n'a pu se soustraire. »(Laplanche, 1967:460).

Tel était le comportement de monsieur Omochi. Tout au long du roman, monsieur Omochi ne cesse pas de hurler et de gronder à tort et à travers même 
quand il rit, comme s'il ne trouvait autre manière de s'exprimer ou de prouver son autorité et son existence que par les cris et les engueulades.

Dégoutée de la physionomie du vice-président, la jeune romancière n'a pas de lui attribuer des épithètes et des métaphores qui indiquent son poids pesant comme "la montagne de chair», "l'énorme Omochi, ", "La masse de chair du viceprésident », " le monstre, 》, " un obèse colérique » et "l'ogre »(Nothomb,1999:86108-109-110-169).

Méchant et agressif par nature, ce vice-président féroce refuse obstinément la moindre transgression des ordres ou des lois établies dans l'entreprise et n'hésite pas un instant à châtier cruellement toute personne osant entraver le progrès et le développement de la compagnie.

Rien n'est plus surprenant que son attitude agressive avec sa subordonnée Fubuki. Intransigeant et violent, le vice-président, pour reprocher à sa subordonnée une faute, il l'a submergée d'un torrent d'insultes et des paroles diffamatoires dans un spectacle inhumain devant tous ses collègues «Un beau jour, nous entendîmes au loin le tonnerre dans la montagne: C'était monsieur Omochi qui hurlait. [...]. Il cria d'une voix d'ogre réclamant son déjeuner: Fubuki-San![...]. Le monstre voulait qu'elle perdît la face, [...]. Le grondement qui sortait du ventre $d u$ tortionnaire semblait intarissable. »(Nothomb,1999:109-110).

Heureusement les situations qui ont réuni la jeune occidentale avec le vice président étaient peu nombreuses, cependant, ces situations étaient toutes dominées par les rugissements, les beuglements et la fureur de l'ogre.

La première collision entre le vice - président et la jeune occidentale était le jour où la jeune occidentale a servi le thé à la délégation d'une firme amie avec des formules qui révèlent qu'elle comprend la langue japonaise. Après le départ de la délégation, le drame a éclaté, le vice-président s'est mis à hurler d'une voix tonitruante. «Les hurlements de l'obèse résonnèrent derrière le

mur. On ne comprenait pas ce qu'il disait, mais cela n'avait pas l'air gentil. »(Nothomb,1999:19). Ces hurlements ont fini par obliger la jeune occidentale d'oublier la langue japonaise et de ne jamais essayer de parler en japonais.

Le deuxième drame entre le vice-président et la jeune occidentale a éclaté quand la coupable a rédigé le rapport que monsieur Tenshi lui a demandé sur le nouveau beurre allégé. Ce rapport, bien qu'il soit parfaitement excuté par la jeune belge, il était réprouvé par monsieur Omochi qui s'est mis à proférer des accusations calomnieuses et des paroles injurieuses. Dans un spectacle affreux, la jeune belge révèle l'épreuve abominable qu'elle a vécue avec monsieur Tenshi dans le bureau de monsieur Omochi. "Monsieur Tenshi et moi reçûmes des hurlements insensés.[...]. Mon compagnon d'infortune et moi nous fimes traiter de tous les noms : nous étions des traîtres, des nullités, des serpents, des fourbes et - sommet de l'injure - des individualistes. »(Nothomb,1999:42).

Quand monsieur Tenshi a eu la hardiesse d'expliquer au vice-président la situation, afin de se défendre et d'innocenter la jeune belge, l'obèse a hurlé en pleine figure: "vous n'avez jamais eu d'autre but que de saboter la compagnie »(Nothomb,1999:43).

De même quand la jeune belge,incapable de mesurer la dimension de la catastrophe, a eu le courage de se défendre, monsieur Omochi, refusant toute sorte 
de défense, s'est mis à proférer des menaces. «vous, je vous préviens : c'était votre premier et votre dernier rapport. Vous vous êtes mise dans une très mauvaise situation. Sortez! je ne veux plus vous voir! »(Nothomb,1999:46). L'agressivité et le sadisme du vice-président apparaissent par excellence quand il a croisé la jeune occidentale dans les toilettes. Raciste et sadique, l'obèse a exprimé son bonheur et sa joie de voir la jeune belge occuper ce poste humiliant en lui affirmant que le nettoyage des chiottes est la tâche qui convient à son inaptitude et qu'elle le mérite par excellence au lieu d'être payée sans rien faire. Étonnée de l'attitude de monsieur Omochi, la jeune belge n'a pas manqué de nous révéler sa joie. "Le vice-président ne s'inquiétait pas de mon sort. Il fut au contraire le plus enthousiaste quant à ma nomination. [...], il me lançait, jovial. - c'est bien, hein, d'avoir un poste? Il le disait sans aucune ironie.[...]. Q'un être aussi inapte que moi ait enfin une place dans la société constituait à ses yeux un événement positif. »(Nothomb,1999:131).

Le sadisme absolu de monsieur Omochi atteint son paroxysme quand il a découvert le manque de papier-toilette sec dans les toilettes des messieurs. Saisi par une colère terrible, monsieur Omochi s'est mis à hurler comme un fou en lançant des blasphèmes et des menaces à la figure de la jeune belge. L'état de fureur indescriptible de monsieur Omochi était accompagné cette fois-ci de violence suffisante pour jeter la terreur et l'horreur dans le cœur de la jeune stagiaire qui n'a pas manqué de nous transmettre ce spectacle pathétique qui apitoie les cœurs les plus endurcis. "Le vice-président m'attrapa comme King Kong s'empare de la blondinette, [...] m'emportait aux toilettes des messieurs.[...]. Il ouvrit la porte d'un cabinet et me jeta sur les chiottes. "Ton heure est venue, " me dis-je. Au sommet de la fureur, il continuait à crier ces trois sons,[...].-No pêpâ ! No pêpâ!

Le vice-président avait donc choisi cette manière délicate pour m'avertir qu'il manquait de papier dans ce lieu»(Nothomb,1999:141-142).

Ce drame horrible avec le vice-président était suivi d'une autre scène dans son bureau juste avant le terme du contrat de la jeune occidentale. Arrivée enfin la fin de son contrat,la détenue, qui attendait avec une impatience grandissante cette date, devait cependant, selon les règlements du travail au Japon, présenter sa démission à chaque échelon hiérarchique. Malheureusement, le système du travail a imposé à la jeune stagiaire, la rencontre de monsieur Omochi pour la dernière fois dans son bureau afin de lui présenter sa démission. Le drame a éclaté cette fois-ci quand l'obèse, qui était en train d'avaler une grande quantité de chocolat vert dans son bureau, a demandé à la jeune belge d'essayer ce nouveau genre de chocolat blanc au melon vert.

Écœurée de ce genre de chocolat vert, la jeune belge a refusé de l'essayer. Après avoir répété son ordre plusieurs fois à la jeune occidentale qui refuse obstinément de manger, le vice-président, au comble de l'irritation, explosa de colère :

-« dites donc, aussi longtemps que votre contrat n'est pas terminé vous devez m'obéir! [...].

-Insolente! [...] vous devez exécuter mes ordres. »(Nothomb,1999:166).

Autoritaire et sadique, le vice-président s'est ingénié à persécuter et à gêner la jeune stagiaire jusqu'au dernier moment, raison pour laquelle, la pauvre a comparé son attitude agressive à celle du serpent obèse qui a obligé Eve à croquer la pomme 
«Eve n'avait aucune envie de croquer la pomme, mais un serpent obèse, [...], l'y avait contrainte. »(Nothomb,1999:167).

Ajoutons à cette agressivité du vice-président sa moquerie d'Amélie et sa grossièreté avec elle. Ayant reçu sa démission, le vice-président s'est mis à hurler de rire comme si la demande de la jeune occidentale était une demande de fous. Comme ses éclats de rire étaient accompagnés de larmes, le vice-président a tiré un mouchoir de sa poche pour les sécher et pour se moucher sans honte et avec une grossièreté incomparable devant la jeune belge qui était au comble de la stupeur de ce comportement tellement étrange et grossier au Japon.

Bref, par sa démission, la jeune romancière a mis fin à une des plus malheureuses périodes de sa vie où elle a essuyé des rebuffades, des déceptions, et des frustrations.

2-Les différents procédés auxquels Amélie a eu recours pour surmonter les rudes épreuves infligées par ses supérieurs.

Comme elle a tant rêvé de travailler au Japon, la jeune belge s'est donnée beaucoup de peine et a déployé tout son effort pour que cette grande entreprise accepte de l'engager. "J'avais étudié la langue tokyoite des affaires, j'avais passé des tests. [...], mais j'avais toujours éprouvé le désir de vivre dans ce pays auquel je vouais un culte depuis les premiers souvenirs idylliques que j'avais gardés de ma petite enfance. »(Nothomb,1999:22).

Malheureusement, le rêve ne s'est pas réalisé, la vie de la jeune belge au Japon n'était qu'un calvaire marqué par l'humiliation, le mépris et les échecs inévitables.

Incontestablement toute personne raisonnable à la place de la jeune occidentale n'hésite pas un instant à présenter sa démission afin de s'enfuir de cet enfer intolérable, mais la jeune stagiaire, armée d'une volonté de fer et d'une foi inébranlable en ses compétences et ses capacités, a renoncé à l'idée d'annuler le contrat qu'elle avait signé pour un an et a insisté à résister et à persister quel que soit le prix. Autrement dit Amélie a obstinément refusé l'echec «Présenter ma démission eût été le plus logique. Pourtant, je ne pouvais me résoudre à cette idée.[...]. J'étais dans la compagnie depuis un mois à peine. Or j'avais signé un contrat d'un an. Partir après si peu de temps m'eût couverte d'opprobre, à leurs yeux comme aux miens. »(Nothomb,1999:21).

Cette persévérance et ce courage à affronter les obstacles et cette insistance à les franchir sans manifester la moindre souffrance quelle que soit la douleur, n'étaient pas étranges à la jeune belge qui était fortement influencée par la personnalité dynamique et résistante de sa mère comme elle nous déclare : «Je n'ai jamais vu

ma mère mélancolique et pensive, mais courant d'un bout à l'autre de la maison. On a l'impression de voir de l'énergie se déplacer. »(Amanieux,2005:82).

La jeune belge doit son enthousiasme et sa vivacité à sa mère énergique "elle prendra l'habitude dynamique de sa mère de ne pas trop céder au laisser-aller, ou à la souffrance. »(Amanieux,2005:84).

Influencée par la personnalité combative de sa mère et fascinée par la philosophie de "Samouraïs"(2), la jeune occidentale a acquis l'esprit d'initiative, le courage d'assumer la responsabilité de son choix quelles que soient les 
conséquences et l'habitude de ne jamais se plaindre quelles que soient les peines et de ne jamais accepter la défaite quel que soit le prix.

La jeune stagiaire, éblouie par la splendeur et la gloire du Japon dès son enfance, a choisi volontiers le pays du Soleil-Levant pour aller y travailler tout en assumant courageusement tout seule les répercussions de son choix. Au début du roman, Amélie nous déclare: «Après tout, ce que j'avais voulu, c'était travailler dans une entreprise japonaise. J'y étais. »(Nothomb,1999:14).

Et vers la fin du roman, la jeune occidentale, patiente et persévérante, nous révèle encore : "[...] .J'avais à présent sous les yeux l'horreur méprisante d'un système qui niait ce que j'avais aimé et cependant je restais fidèle à ces valeurs auxquelles je ne croyais plus. Je ne perdis pas la face. »(Nothomb,1999:125).

La décision irrévocable de la jeune romancière d'insister à résister et à ne pas perdre la face n'est qu'un témoignage de la supériorité de ses facultés occidentales devant tout le monde.

Pour mieux comprendre l'attitude résistante de la jeune stagiaire et ce comportement stoïque qui l'a aidée à apaiser la mortification et

la souffrance de cette expérience décevante,on a eu recours à ce que la psychanalyse appelle les mécanismes de défense.«A l'origine, en psychanalyse et pour Sigmund Freud les mécanismes de défense désignaient tous les stratagèmes ou procédés dont se sert le Moi dans des conflits éventuellement névrotiques. Ces défenses sont inconscientes et leurs usages résultent du conflit entre la pulsion et le moi et aux caractères inconciliables d'une perception ou d'une représentation (Souvenirs, fantasme, etc...) avec les impératifs moraux (Censure Surmoi). »(Freud,1915:125).

Autrement dit, les mécanismes de défense constituent une forteresse où la jeune belge s'est réfugiée afin d'échapper à ses douleurs et à ses tourments.

\section{1- L'humour}

Parmi les mécanismes de défense qui ont aidé Nothomb à faire face aux humiliations et aux tourments qu'elle a subis au Japon c'est l'humour.En proie à d'insupportables épreuves, la jeune occidentale a eu recours à l'humour afin d'alléger ses souffrances, d'atténuer la sècheresse de ce système rigoureux et austère et de briser l'ennui et l'amertume de son expérience éprouvante.

L'humour comme mécanisme de défense « est la plus haute des réalisations des défenses. Réponse soulignant les aspects amusants et ironiques des conflits, l'humour permet de prendre une distance par rapport aux choses. »(Freud,1915:138).

Dans cette optique Katelyn Sylvester nous révèle"chez Nothomb,l'ironie,[...], lui permet de s'affirmer malgré les situations oppressives et contraignantes dans lesquelles elle se trouve, ainsi que de renverser les rapports de pouvoir entre personnages."(Sylvester,2008:6-7) .

Quant à Laureline Amanieux, elle affirme que "L'ironie est son instrument de prédilection, souvent sévère et glacial. Pas de place pour la douceur, l'aseptisation, le morne: les mots doivent briller, et brûler le cerveau. Le verbe, plus que les actes, est armé au point de tuer. »(Amanieux,2005:144).

Quant à Amélie Nothomb, elle avoue dans l'un de ses entretiens : «Plus je parle de sujets graves, plus j'en parle légèrement. »(Amanieux,2005:284) . 
L'humour de la jeune belge apparaît par excellence dès la première épreuve qui consiste à rédiger une lettre d'invitation à un certain Adam Johnson à jouer au golf avec monsieur Saito. Désespérée de satisfaire monsieur Saito qui a avorté toutes ses tentatives, la jeune belge a commencé à s'amuser en répétant plusieurs fois inconsciemment la même lettre dont elle savait d'avance le sort .

La répétition inutile de cette lettre a poussé la jeune occidentale à exprimer sa souffrance à travers 1 ' humour. "Jecommençais à m'amuser quand mon supérieur m’interrompit. Il déchira la énième lettre sans même la lire.[...]. »(Nothomb,1999:12). De même la jeune belge s'est réfugiée dans l'humour afin d'échapper à ses déconvenues quand monsieur Saito lui a demandé d'oublier la langue japonaise après avoir dérangé la délégation d'une firme amie en présentant le thé honorable avec des formules qui révèlent qu'elle comprend la langue japonaise.

Soumise à l'ordre injuste et raciste de monsieur Saito, la jeune romancière a commencé à servir "les diverses tasses de thé et de café sans l'ombre d'une formule de politesse et sans répondre aux remerciements des cadres. Ceux-ci n'étaient pas au courant de mes nouvelles instructions et s'étonnaient que l'aimable geisha blanche se soit transformée en une carpe grossière comme une yankee. »(Nothomb,1999:26).

Choquée par la décision irrévocable et inique de monsieur Saito, la nouvelle stagiaire exprime par l'humour la dégradation de son état d'une geisha qui est «au Japon, danseuse, musicienne et chanteuse traditionelle qui joue le rôle d'hôtesse, de dame de compagnie, dans certaines occasions de la vie sociale, »(Amiel,1989:501). qui est devenue sous l'emprise de son supérieur une carpe qui est un gros poisson d'eau douce connu par certains proverbes qui indiquent la nonchalance et l'indolence comme "être, rester muet, silencieux comme une carpe, ne pas prononcer un mot. Baîller comme une carpe largement et fréquement. »(Amiel,1989:159).

La jeune stagiaire a continué à exprimer sa désapprobation par l'humour, quand monsieur Saito lui a permis d'ajuster les calendriers de la compagnie. Ce travail subalterne a excité les rires de tous les employés de l'entreprise qui n'ont pas manqué de se moquer d'elle en lui demandant

- «ça va? vous ne vous fatiguez pas trop à cet épuisant exercice? »(Nothomb,1999:29).

La jeune stagiaire ne trouve que l'humour comme réponse à cette question exaspérante :

-C'est terrible. Je prends des vitamines. »(Nothomb,1999:29).

L'humour de la jeune belge trouve son plein épanouissement quand elle nous décrit la manière avec laquelle elle arrachait la page de mois de février. "J'assassinais les mois de février avec de grands gestes de Samourä̈, minant une lutte sans merci contre la photo géante du mont Fuji enneigé qui illustrait cette période dans le calendrier Yumimoto. Puis je quittais les lieux du combat, l'air épuisé, avec des fiertés sobres de guerrier victorieux, sous les banzaï des commentateurs enchantés. »(Nothomb,1999:30).

Ayant perdu l'espoir d'occuper un poste considérable dans cette grande entreprise où elle est considérée comme un sous-fifre, la jeune stagiaire a essayé 
avec les gestes humouristiques de donner une valeur et une importance à cette tâche inutile.

L'humour de la jeune belge apparaît également à travers les éclats de rire avec lesquels elle accueillait la méchanceté de monsieur Saito quand il l'a obligée de photocopier milles pages sans se servir de l'avaleuse sous prétexte qu'elle n'est pas précise, en outre, il a refusé toutes ses tentatives de perfectionner son travail et l'a obligée de répéter la photocopie des pages une par une plusieurs fois ce qui a excité le rire de la jeune stagiaire. «J'éclatai de rire [...]. Je suis sûre qu'il n'a même pas regardé mes nouvelles photocopies. Je les ai faites une par une, calibrées au millimètre prés. »(Nothomb,1999:35).

Quelques pages ultérieures,on trouve Nothomb incapable de s'empêcher de rire quand monsieur Saito a jeté la liasse qu'elle a photocopiée à la poubelle et lui a demandé de recommencer. "Je courbai la tête et m'exécutai. J'avais du mal à m'empêcher de rire. »(Nothomb,1999:39).

De même, Amélie a eu recours à l'humour pour exprimer sa stupeur quand sa supérieure directe mademoiselle Fubuki lui a annoncé sa nouvelle affectation dans la section comptabilité «J'eus envie de rire: Comptable, moi? pourquoi pas trapéziste »?(Nothomb,1999:54).

Résignée aux ordres de sa supérieure, la jeune occidentale qui souffre «d'une rare stupidité face aux chiffres »(Nothomb,1999:69), a déployé un effort considérable afin de pouvoir surmonter les difficultés et les obstacles qu'elle trouve devant les chiffres et les nombres. Pour dissiper le malaise qui s'emparait d'elle en travaillant dans le domaine de comptabilité,la jeune stagiaire exprime sa maladresse par l'humour «Les chiffres, dont j'avais toujours admiré la calme beauté pythagoricienne, devinrent mes ennemis. La calculette aussi me voulait du mal. »(Nothomb, 1999:68).

Errante dans le labyrinthe des chiffres, la jeune apprentie exprime son désarroi et son malaise toujours par l'humour. "Je commençais par regarder chaque nouveau nombre avec autant d'étonnement que Robinson rencontrant un indigène de ce territoire inconnu, ensuite, ma main gourde essayait de le reproduire sur le clavier. »(Nothomb,1999:69).

Pour pouvoir terminer son travail avant la date d'échéance, la jeune belge se trouve obligée de passer trois nuits blanches à l'entreprise affrontant toute seule son destin ténébreux avec tant de chiffres et de nombres par l'humour et le rire qui accompagnent toujours ses souffrances. "En vérité, à cause du manque de sommeil, je riais pour un rien. J'avais parfois des coups de fatigue et de découragement, mais je ne tardais jamais à retomber dans mon hilarité. »(Nothomb,1999:73).

La répétition successive et inutile des erreurs et des fautes pousse Amélie à éclater de rire en disant: "Mon tonneau des Danaïdes ne cessait de se remplir de chiffres que mon cerveau percé laissait fuir. »(Nothomb,1999:73).

L'enthousiasme et la persévérance de la jeune belge l'ont motivée à répéter sans relâche des tentatives inutiles espérant trouver une issue de cette impasse. Cependant l'acharnement de la jeune enthousiaste n'avait aucun profit et il était voué à l'échec qui était également accompagné d'humour en comparant son état lamentable au tonneau des Danaïdes «qui est un travail interminable et désespérant référence à la mythologie grecque et au tonneau sans fond que les Danaïdes furent 
condamnées à remplir pour avoir égorgé leur mari la nuit de leurs noces. »(Amiel,1989:1110).

Excédée de fatigue,Amélie se compare à un autre héros mythique afin de nous révéler qu'elle était condamnée à répéter un travail éreintant et infini en disant : "J'étais le "Sisyphe »" de la comptabilité et, tel le héros mythique, je ne me désespérais jamais, je recommençais les opérations inexorables pour la centième fois, la millième fois. »(Nothomb,1999:73).

La jeune stagiaire a poursuivi sa résistance au supplice qu'elle a subi dans la géhenne japonnaise par l'humour,quand elle a accepté de nettoyer les toilettes de l'entreprise au lieu de présenter sa démission pour ne pas perdre la face. " De deux maux, il faut

choisir le moindre.[...].Entre extraire de ma calculette,[...] des nombres[...],et extraire des rouleaux de papier-toilette du débarras,je n'hesite pas.»(Nothomb,1999:125-126).

Obsédée d'un désir ardent de se réaliser dans cette grande entreprise même en occupant les postes les plus infâmes et les plus vils, la jeune enthousiaste,pour ne pas sombrer dans le désespoir, "raconte cela avec sa douce ironie,sa causticité bien sentie,jusqu'à quel point elle est allée et a assumé la position,un peu comme les militaires disent"tenir une position".(David,2006:140).

Afin de sortir de sa position d'impuissance, la jeune belge se lamente sur son sort et son nouveau poste par l'humour exprimé par son style métaphorique qui compare les lieux des commodités à un ministère . "Le matin, quand le métro me conduisait à l'immeuble Yumimoto, j'avais déjà envie de rire à l'idée de ce qui $m$ 'attendait. Et lorsque je siégeais en mon ministère, je devais lutter contre de furieux accès de fou rire. »(Nothomb,1999:127).

Rien n'est plus humouristique que la formule comique que Nothomb a choisi pour présenter sa démission à chacun de ses supérieurs. "La compagnie Yumimoto m'a donné de grandes et multiples occasions de faire mes preuves. Je lui en serai éternellement reconnaissante. Hélas, je n'ai pas pu me montrer à la hauteur de l'honneur qui m'était accordé. »(Nothomb,1999:156).

Respectant jusqu'au dernier moment les traditions et les règlements du système rigide du travail au Japon, la jeune belge,tient en expliquant les raisons de sa démission, à suivre la grande règle qui consiste à ne jamais se plaindre.

L'humour de la jeune stagiaire apparaît par excellence quand elle a décidé de suivre l'ancien protocole nippon qui l'oblige à s'adresser à sa supérieure avec stupeur et tremblements. "Je pris donc le masque de la stupeur et je commençai à trembler. »(Nothomb, 1999:160).

Même en quittant le travail, la jeune belge se trouve obligée de manifester toutes les marques d'humiliations devant sa supérieure comme «les samouraïs quand ils s'adressent à leur chef, la voix traumatisée par un respect surhumain»(Nothomb,1999:160)

La jeune stagiaire a continué à s'exprimer par l'humour même quand sa supérieure directe lui a demandé à la fin de son stage « [...], quel métier pourriezvous exercer? » La jeune belge lui a répondu ironiquement "-Croyez-vous que l'on voudra de moi au ramassage des ordures?»(Nothomb,1999:160). 
Bref, l'humour est resté une arme défensive qui a aidé Nothomb à franchir les obstacles et à endurer les souffrances jusqu'à la fin de son calvaire.

\section{2-La compensation}

La compensation est le deuxième mécanisme de défense auquel la jeune belge a eu recours pour pouvoir apaiser sa douleur et sa souffrance durant un an dans une entreprise où « elle a subi chaque jour des humiliations absurdes et où elle était l'objet de tous les mépris. »(Nothomb,1999:85).

D'après la psychanalyse, la compensation « est une procédure qui vise à négativer, voire à annuler les effets perturbateurs d'un complexe, à rendre celui-ci inopérant en développant des composantes appartenant à un complexe contraire, infériorité - supériorité, échec-réussite, auto-effacement - mise en avant, avidité sobriété ... »(Fernandez-zoïla,1993:95).

En parlant de la compensation comme un procédé auquel Amélie a eu recours pour dissiper les ténèbres de sa vie, il était indispensable de parler de l'impact de ce grand philosophe allemand Nietzsche sur la formation et le développement de la pensée de la jeune romancière.Influencée par la philosophie de Nietzsche, qui a nourri sa pensée et a fertilisé son esprit, Nothomb répétait souvent sa maxime célèbre. "A l'école de guerre de la vie - ce qui ne me fait pas mourir me rend plus fort. De même mourir elle ajoute : Finalement, je dois être résistante. J'ai mis mon corps à rude épreuve. »(Amanieux,2005:244)

Dans cette optique, Laureline Amanieux nous révèle que "La lecture de Nietzsche encourage Amélie à considérer la vie sous un point de vue esthétique. Ce critère est dominant dans son œuvre. Les lieux, les objets, les idées et les êtres sont jugés à travers lui. »(Amanieux,2005:245).

La pensée de Nietzsche a aidé la jeune occidentale à résister et l'a encouragée à s'adapter facilement à ses circonstances pénibles et à supporter toutes les douleurs et les peines dont elle a tant souffert pendant son stage lamentable au Japon. Passionnée et influencée par Nietzsche, la jeune romancière nous a transmis ses idées compensatoires qui ont apaisé sa souffrance et l'ont consolée de ses peines. "Il est typique des êtres qui exercent un métier lamentable de se composer ce que Nietzsche appelle un arrière-monde, un paradis terrestre ou céleste auquel ils s'efforcent de croire pour se consoler de leur condition infecte. »(Nothomb,1999:150).

À l'instar de la philosophie de Nietzsche, la jeune stagiaire qui vivait dans l'abjection et l'avilissement, a décidé de transformer le nid de guêpes où elle est fourrée en un paradis pour pouvoir persister comme elle nous révèle. " [...] Pour supporter [...], je devais changer de références, je devais inverser ce qui jusque-là m'avait tenu lieu de répères. [...]. Aussitôt, dans ma tête, le sale devint le propre, la honte devint gloire, le tortionnaire devint la victime et le sordide devint le comique. »(Nothomb,1999:127).

La création compensatoire de la jeune belge trouve son plein épanouissement à travers ce qu'elle appelle «Se jeter dans la vue ou "exercice de défenestration »(Nothomb,1999:27). qu'elle pratiquait fréquemment au point de devenir une habitude.

L'omniprésence de cette habitude tout au long du roman n'est qu'un bon témoignage de son désir ardent et son besoin impérieux de s'enfuir de cette geôle où 
elle est emprisonnée et tourmentée et de respirer à pleins poumons l'air de liberté loin de tous les ordres et les autorités de ce système cruel et rigoureux comme nous révèle Amanieux «Lorsque Amélie - San, [...], joue à "se jeter dans la vue », elle exerce une décorporation en voulant dissoudre son corps dans l'air : "son unique porte de sortie se trouve dans un impossible et intenable néant, celui d'un esprit qui transcende le corps. »(Amanieux,2005:186) . Dès son arrivée à l'entreprise, la jeune stagiaire éprouve une vive admiration pour le vide à travers la baie vitrée du quarante-quatrième étage. "En vérité, il n'y avait dans ma tête aucune pensée, rien que la fascination pour le vide, par la baie vitrée, »(Nothomb,1999:8).

La baie vitrée du dernier étage de ce gratte-ciel est devenue son refuge où elle se trouvait dans une position de supériorité,de puissance et de domination de l'univers tout entier comme un oiseau qui s'envolait dans l'espace en pleine liberté, en pleine nature et en pleine joie. Fascinée par le vide à travers la baie vitrée de l'entreprise, la jeune belge guettait la chance qui lui permettait de jouer ou de s'amuser en se jetant dans la vue afin de se débarrasser de ses peines et de ses soucis. Pour satisfaire cette passion de défenestration, la jeune belge, ignorant toujours son rôle dans la compagnie japonaise, a pris l'initiative de distribuer le courrier sans demander l'avis ou la permission de personne. Cette tâche insignifiante lui permettait d'utiliser l'ascenseur qui se trouvait juste à côté de la baie vitrée qu'elle adorait. "Avec mon chariot, [...], je ne cessais d'emprunter l'ascenseur. J'aimais cela car juste à côté, [...], il y avait une immense baie vitrée. Je jouais alors à ce que j'appelais " me jeter dans la vue ». Je collais mon nez à la fenêtre et me laissais tomber mentalement. La ville était si loin en dessous de moi : avant que je ne m'écrase sur le sol, il m'était loisible de regarder tant de choses. »(Nothomb,1999:27-28)

Ce jeu amusant que Nothomb a créé pour s'enfuir de l'amertume de sa vie, l'a aidée à supporter les trois nuits blanches qu'elle a passées avec la calculette au milieu des chiffres et des nombres. «c'etait ma troisième nuit blanche d'affilée, [...]. Je me levai. J'étais libre. [...]. Je marchai jusqu'à la baie vitrée. La ville illuminée était très loin au-dessous de moi. Je dominais le monde. J'étais Dieu. Je défenestrai mon corps pour en être quitte. »(Nothomb,1999:76).

C'est grâce à cette baie vitrée que la jeune stagiaire a pu tolérer, sans la moindre plainte, sept mois à nettoyer les toilettes de la compagnie Yumimoto. "Les toilettes [...] de la compagnie [...] étaient éclairées d'une baie vitrée. Cette dernière avait pris dans mon univers une place colossale: Je passais des heures debout, le front collé à verre, à jouer à me jeter dans le vide.[...]. Pour cette raison, j'affirme que je ne me suis jamais ennuyée une minute à mon poste. »(Nothomb,1999:141).

Cet exercice, qui est devenu une habitude consolatrice, a accompagné la jeune romancière jusqu'à son dernier jour à l'entreprise. Le jour de son départ, Nothomb n'a pas manqué de faire ses adieux à la baie vitrée qui lui permettait de dominer ce monde et d'évacuer ses pressions psychiques et nerveuses provoquées par le système corrosif qui lui a été imposé pendant son stage qui a duré un an «D'instinct, je marchai vers la fenêtre. Je collai mon front à la vitre et je sus que c'était cela qui me manquerait: Il n'était pas donné à tout le monde de dominer la ville du haut du quarante - quatrième étage. [...]. Une ultime fois, je me jetai dans le vide. Je regardai mon corps tomber. Quand j'eus contenté ma soif de 
défenestration, je quittai l'immeuble Yumimoto. On ne m'y revit jamais. »(Nothomb,1999:173-174). Jusqu'à la fin de son contrat, la baie vitrée était la première et la dernière chose qu'elle a vue dans cette entreprise et la seule chose qui l'a fascinée dans cette expérience accablante. La création compensatoire de la jeune belge ne se manifeste pas à travers la baie vitrée seulement mais elle prend d'autres formes. Rien n'est plus expressif que son comportement fabuleux pendant la troisième nuit blanche qu'elle a passée toute seule dans l'entreprise espérant terminer son travail de comptabilité avant la date d'échéance. Cette nuit de folie n'est qu'un défoulement de l'angoisse et du malaise qui s'emparaient d'elle en travaillant dans ce domaine.

Pour s'échapper de cette ambiance étouffante, Amélie a créé une atmosphère compensatoire qui peut l'aider à sortir de son désarroi et lui permet de se réaliser face aux autorités et d'être dans une position de pouvoir et de supériorité . « J'éteignis les néons.[...], je délaçai mes souliers [...]. Je sautai sur un bureau, puis de bureau en bureau en poussant des cris de joie. J'étais si légère que les vêtements m'accablaient. Je les enlevai un à un et les dispersai autour de moi. Quand je fus nue, je fis le poirier - [...]. Sur les mains, je parcourus les bureaux adjacents. Ensuite, je bondis et me retrouvai assise à la place de ma supérieure. [...], je suis Dieu [...], moi je règne. » (Nothomb,1999:77) . Désespérée d'accomplir cette tâche de comptabilité qui va à l'encontre de ses compétences linguistiques, Amélie, au comble de sa souffrance, s'imagine qu'elle est devenue le Christ. «Il y a eu le Christ aux oliviers, moi je suis le Christ aux oridinateurs. » et l'ordinateur de sa supérieure Fubuki prend "l'apparence d'une statue de l'île de Pâques. »(Nothomb,1999:78).De même la jeune novice a essayé autant que possible de compenser sa déficience et sa maladresse devant les chiffres et les nombres en imaginant la calculette, cet appareil gênant pour elle,comme un instrument musical tel que le piano espérant effectuer les opérations de calcul sans fautes et obtenir de bons résultats sans de graves erreurs. «Depuis que j'ai quitté le monde séculier pour entrer dans les ordres, le temps a perdu toute consistance et s'est mué en une calculette sur laquelle je pianote des nombres bourrés d'erreurs. »(Nothomb,1999:78).

Toujours incapable de faire le moindre progrès, la jeune novice, en vue de compenser sa faillite, compare sa souffrance à celle du Christ en s'imaginant qu'elle est crucifiée afin de donner une valeur et une importance à son supplice et d'en faire une gloire et un honneur" Moi aussi, je suis une pauvre crucifiée.[...]. Ils m'ont martelé le corps de tant de nombres qu'il n'y a plus place pour la moindre décimale.[...]. Au matin, mes bourreaux arriveront et je leur dirai : "J'ai failli! Tuez-moi»(Nothomb,1999:79). .La création compensatoire de la jeune stagiaire atteint son paroxysme quand sa supérieure lui a infligé la dernière affectation celle de nettoyer les toilettes. Pour s'adapter à ce poste subalterne et abject, la jeune belge s'est efforcée de se consoler et de se patienter en glorifiant le lieu de son travail pour lui donner une valeur et une appréciation: "Ouvre les yeux : que pèse la chair de ces précieux humains face à l'éternité de la faïence des sanitaires? Rappelle-toi ces photos de villes bombardées : les gens sont morts, les maisons sont rasées, mais les toilettes se dressent encore fièrement dans le ciel, [...]. Quand l'Apocalypse aura fait son cuvre, les cités ne seront plus que des forêts de chiottes. »(Nothomb,1999:149). 
Pour vaincre ce sentiment de malaise qui l'envahissait, la jeune occidentale, s'acharne de se convaincre que le destin des employés de la compagnie Yumimoto est plus pire que le sien et que le nettoyage des toilettes avec la brosse à chiottes est beaucoup plus mieux que la comptabilité avec sa calculette et ses chiffres. "Les comptables qui passaient dix heures par jour à recopier des chiffres étaient à mes yeux des victimes sacrificées sur l'autel d'une divinité dépourvue de grandeur et de mystère.[...], qu'est-ce qui attendait les comptables au cerveau rincé par les nombres? [...] une épouse déjà endormie, des enfants déjà lassés, le sommeil qui vous aspire comme un lavabo qui se vide, les rares vacances dont personne ne connaît le mode d'emploi [...]. Le pire, c'est de penser qu'à l'échelle mondiale ces gens sont des privilégiés.»(Nothomb,1999:152-153).

\section{3-La sublimation.}

Le troisième mécanisme de défense qui a aidé Nothomb à faire face au harcèlement moral et psychique qu'elle a subi au pays du Soleil-Levant,est la sublimation. "La sublimation comme mécanisme de défense répond à un déplacement avec résituation dans un autre secteur de l'activité. La sublimation est la capacité de satisfaire la pulsion sans atteindre le but originel, la sublimation est à l'œuvre dans les processus sociaux comme l'art ou bien les sports. Parmi les défenses, la sublimation occupe un staut particulier, puisqu'elle ne nécessite pas de refoulement. Une pulsion consciente peut trouver sublimation.» (Laplanche,1967:465).

En effet tous les événements du roman se déroulent dans une entreprise où règne une atmosphère rigoureuse et implacable due à un système du travail qui écrase l'individu. Cependant, Nothomb, envoutée par la nature, a pu s'enfuir de cette atmosphère angoissante en évoquant quelques indices de la nature nippone qui a laissé des traces indélébiles dans sa mémoire. A ce propos, Corina da Rocha Soares nous révèle que "la présence d'échos écologiques dans les romans autobiographiques de l'écrivain belge Amélie Nothomb pourrait viser, par exemple, une défense de la nature vue comme un temple de la divinité ou comme un véhicule d'accès à la paix spirituelle. »(Soares,2007:92).

Dans une interview publiée dans le journal Le Point, quand la journaliste a révèlé à la jeune romancière que la nature est peu présente dans ses livres, elle lui a répondu : "Mais quand elle l'est, elle y prend une place phénoménale. Cela se sent surtout dans mes livres japonais...[...] La nature nous donne l'exemple, parce que la nature va toujours au plus difficile. J'y songe beucoup. Au plus complexe de mes livres, il y a la nature, même si je n'en parle pas expressément. »(Leclere,2008:8).

Pour pouvoir se soumettre à l'ordre illogique de monsieur Saito qui l'a forcée d' oublier la langue japonaise, la jeune belge n'a trouvé autre solution que de dissimuler la langue japonaise derrière les différentes langues qu'elle maîtrise en comparant ces langues à une forêt avec sa variété d'espèces d'arbres : «Si le langage était une forêt, m'était-il possible de cacher, derrière les hêtres français, les tilleuls anglais, les chênes latins et les oliviers grecs, l'immensité des cryptomères nippons, qui en l'occurrence eussent été bien nommés? »(Nothomb,1999:22).

Comme elle ignorait sa position dans la compagnie Yumimoto, Nothomb, essayant de remplir son temps souvent vide, a laissé la bride à son imagination pour se rappeler ce qu'elle appelle. «lieux mythologiques» où elle a passé ses cinq 
premières années "L'évocation de ces lieux mythologiques me mettait les larmes aux yeux [...]. C'était là[...] que battait mon cour depuis ce jour où, à l'âge de cinq ans, j'avais quitté les montagnes nippones pour le désert chinois. »(Nothomb, 1999:25) .En fouillant dans ses souvenirs d'enfance, la jeune belge n'arrive pas à croire que ces lieux si chers à son cœur et où elle a passé ses plus belles années se trouvent dans le même pays où elle a vécu une expérience douloureuse marquée par la descente effrénée aux enfers. La sublimation apparaît également chez la jeune occidentale à travers l'admiration qu'elle manifestait à l'égard de sa tortionnaire Fubuki qui s'est ingéniée à la tourmenter et à l'humilier par tous les moyens possibles.

Fascinée par la beauté séduisante de sa supérieure Fubuki ,la jeune stagiaire ne cessait pas de vanter ses charmes"qui font d'elle une cuvre d'art inaccessible à l'entendement."(Nothomb,1999:87).

L'impact colossal de la beauté frappante de Fubuki sur sa subordonnée apparaît clairement quand cette dernière était surchargée par la tâche qui concerne la classification des factures par ordre de date. C'est la beauté de Fubuki qui a chargé la jeune belge d'une énergie positive pour endurer le supplice « Ainsi, en consignant les facutres, je relevais souvent la tête pour rêver en admirant le si beau visage de ma dénonciatrice[...]. Noter des nombres en regardant la beauté, c'était le bonheur. »(Nothomb, 1999:56).

L'effet magique de la beauté extrême de la supérieure sur la jeune stagiaire se renouvelle quand Fubuki lui a infligé le travail dans la section comptabilité. Déprimée par son état d'impuissance devant les opérations de calcul et les chiffres,Amélie tâche de trouver dans la beauté de sa supérieure une sublimation pour ses échecs successifs et incontournables comme elle nous déclare. «Il n'était pas rare qu'entre deux additions je reléve la tête pour contempler celle qui m'avait mise aux galéres. Sa beauté me stupéfait. 》(Nothomb.1999:74)

Cette admiration ne se réduit pas seulement à la contemplation mais elle a dépassé cette limite pour arriver à l'imagination. Éblouie par la beauté de sa supérieure, Nothomb a lâché la bride à son imagination pour faire quelques retouches à sa belle supérieure qui la rendaient plus belle et plus séduisante «Alors, je me livrais à un délicieux exercice : je la décoiffais mentalement. A cette chevelure éclatante de noirceur, je rendais la liberté. Mes doigts immatériels lui donnaient un négligé admirable. Parfois, je me déchaînais, je lui mettais les cheveux dans un tel état qu'elle semblait avoir passé une folle nuit d'amour, cette sauvagerie la rendait sublime. »(Nothomb,1999:74) .Nothomb n'a pas cessé d'admirer les charmes de Fubuki même pendant son absence quand elle a passé trois nuits blanches dans l'entreprise toute seule pour accomplir son travail de comptabilité. C'est ainsi qu'elle nous évoque «J'enlace l'ordinateur de Fubuki et le couvre de baisers. »(Nothomb, 1999:79).

La jeune admiratrice tient à aduler sa belle supérieure même dans les toilettes. Rien n'est plus étonnant que son attitude bizarre face aux sentiments hostiles de sa supérieure qui s'obstinait à

fréquenter les toilettes plusieurs fois par jour afin de la gêner pendant son travail. Profitant de la présence régulière de la belle tortionnaire dans les toilettes, la jeune stagiaire continue à louer son envoûtement, sans cesse en accueillant sa 
rancune et sa haine par la joie et l'admiration. «Fubuki croyait me déranger alors qu'au contraire j'étais ravie d'avoir de si nombreuses occasions d'admirer sa beauté orageuse en ce gynécée qui nous était particulier.[...] »(Nothomb,1999:134).

Arrivé le jour de son départ, Nothomb qui, par amour-propre, se trouvait incapable de saluer sa supérieure avant son départ, a éprouvé un profond regret d'avoir raté l'occasion de jouir de sa beauté énivrante pour la dernière fois. « [...]:préférer son orgueil à la contemplation d'un visage exceptionnel, c'était un mauvais calcul. »(Nothomb,1999:173) .La sublimation trouve son plein épanouissement chez la jeune romancière à travers l'écriture qui représente pour elle un refuge auquel elle peut s'évader. La jeune romancière a essayé de défouler toutes ses souffrances à travers l'écriture. Influencée par le philosophe allemand Nietzsche, la jeune romancière a appris à domestiquer son énergie et à la canaliser dans l'écriture comme elle nous déclare dans l'un de ses entretiens «Il y avait tellement d'agressivité en moi. Nietzsche m'a montré que cette énergie, on pouvait en faire autre chose. J'avais un excès d'énergie.[...]. Donc, j'ai appris que cette énergie, il fallait la sublimer et la sortir. Nietzsche m'a vraiment sauvée parce que je suis sûre que si je n'avais pas commencé à écrire, j'aurais vraiment fini par mourir. »(Amanieux, 2005:300)

Dans cette optique Laureline Amanieux, ajoute que "l'écriture de la jeune romancière provient de l'accumulation de très nombreux manques passés et présents.[...]. Nothomb a le sentiment d'avoir découvert la possibilité d'être heureuse à l'âge adulte, en écrivant beaucoup. [...]. Nothomb développe dans sa vie un certain eudémonisme, cette philosophie qui consiste à détourner la souffrance de la réalité, à la transformer en une valeur positive pour en tirer le meilleur. »(Amanieux,2005:303-305)

La jeune romancière accorde à l'écriture un intérêt de première importance. Pour elle «L'écriture est la continuation de l'enfance par d'autres moyens. Il s'agit bien d'apporter au corps de l'adulte le plaisir dont le corps de l'enfant pouvait jouir sans culpabilité. »(Rabaudy,1999:7).

Le temps sacré que la jeune romancière consacre à l'écriture est tellement important qu'elle organise une cérémonie inaltérable qui se déroule entre quatre heures et huit heures du matin comme elle nous révèle «Dans ces moments-là, je vis un état extrême. Je suis dans une transe intellectuelle, une jouissance mentale totale.[...]. Chaque matin, je bois un demi-litre de thé brûlant très fort que du café turc. Cela fait exploser mon cerveau, et rend mon estomac malade, mais il s'habitue ... Écrire est ma première nécessité. C'est mon hygiène. »(Bainbrigge,2001:180)

L'écriture pour la jeune romancière est une source intarissable de ravissement et de jouissance comme elle nous révèle dans Hygiène de l'assassin "Ecrire, ce n'est pas chercher à communiquer. Vous me demandez pourquoi écrire, et je vous réponds très strictement et très exclusivement ceci : pour jouir. » (Nothomb,199 2:71).

Ce penchant irrésistible que la jeune romancière éprouve vers l'écriture et cette profonde satisfaction qu'elle ressent en ressuscitant ses souvenirs même les plus douloureux et en concrétisant ses idées, ses sentiments et ses impressions remontent à ce que la psychanalyse appelle «le principe de plaisir» qui a pour but d'éviter le déplaisir et de procurer le plaisir. En tant que le déplaisir est lié à l'augmentation 
des quantités d'excitation et le plaisir à leur réduction, le principe de plaisir est un principe économqiue. »(Laplanche,1967:332).

Passionnée par l'écriture, la jeune romancière considère chacune de ses œuvres comme une grossesse «Je dis toujours: mes grossesses, ce sont mes enfants de papier. »(Amanieux,2005:264). Cette métaphore affirme que sa production littéraire prolifique est la préoccupation dominante qui la rend heureuse et satisfaite L'écriture permet à la jeune occidentale de sonder les profondeurs de son âme afin d'évacuer ses surcharges et de défouler ses douleurs et ses souffrances et de les remplacer par une sorte de plaisir et de jouissance comme nous déclare Laureline Amanieux «Nothomb pratique une plongée savamment orchestrée dans l'immonde, non pour se punir mais pour se purifier. »(Amnieux,2005:267) De même l'écriture est pour Amélie un moyen de domination, de puissance et surtout de liberté. "L'écriture est, pour Nothomb, un désir de reprendre le pouvoir sur ce qui tente toujours de prendre le pouvoir en elle de redistribuer à son gré les coups et les points, c'est la menace foudroyante toujours à portée de mots. »(Amanieux,2005:268).

Fascinée par l'écriture, la jeune occidentale, productive et énergique, s'est ingéniée à affranchir ses sentiments et ses pensées à travers sa production littéraire. A la fin du roman, la jeune stagiaire a insinué qu'elle écrivait des manuscrits et les dernières lignes du roman annoncent fièrement la victoire de la supériorité du cerveau occidental "Quelques jours plus tard, je retournai en Europe. Le 14 Janvier 1991, je commençai à écrire un manuscrit dont le titre était Hygiène de l'assassin. [...]. En 1992, mon premier roman fut publié. En 1993, je reçus une lettre de Tokyo. Le texte en était ainsi libellé :

Amélie - San

FélicitationsMori Fubuki

Ce mot avait de quoi me faire plaisir. Mais il comportait un détail qui me ravit au plus haut point : il était écrit en japonais. »(Nothomb,1999:174-175).

La sublimation à travers l'écriture atteint son paroxysme quand la jeune belge, après son réveil de son cauchemar affreux, a courageusement décidé de transmettre à tous ses lecteurs son expérience malchanceuse et ses déconvenues infinies dans un pays civilisé comme le Japon à travers ce roman Stupeur et tremblements qui nous a donné une leçon de patience, de persévérance et de dignité au sens strict du terme.

Si puissante qu'elle soit, la jeune stagiaire est enfin un être humain qui lui arrive de passer par des moments de faiblesse où elle se sent incapable de résister. Il était difficile de terminer notre étude sans évoquer ce spectacle pathétique qui a suivi le drame de la jeune belge avec monsieur Omochi dans les toilettes quand il a découvert le manque de papier dans ce lieu. Dans un état de faiblesse irrésistible, la jeune belge s'est livrée à ses larmes pour se décharger de ses dépressions nerveuses. "L'âme en lambeaux, j'allai me réfugier dans les toilettes des dames. Je m'accroupis dans un coin et me mis à pleurer des larmes analphabétes. »(Nothomb,1999:142).

\section{Conclusion :}

$\mathrm{Au}$ terme de notre étude et après avoir étudié ce roman autobiographique,on peut conclure que Nothomb a réussi à mettre en evidence le système rigoureux qui 
domine le monde du travail au japon.Dans Stupeur et tremblements, Amélie Nothomb explore son expérience poignante marquée par la souffrance et l'affliction qu'elle a subies durant son stage pratique au Japon.En proie à d'innombrables et d'insupportables épreuves,la romancière s'est ingéniée à braquer la lumière sur le calvaire qu'elle a enduré dans la grande entreprise japonaise.Pour faire face aux défis et aux persécutions infligés par ses supérieurs, Nothomb,cette combattante courageuse, a eu recours à des différents procédés afin de persister jusqu'à la fin de son contrat dans le pays du Soleil-Levant.Ce roman pathétique met l'accent sur le monde du travail au Japon qui représente un nouveau terrain qui mérite d'être exploré dans d'autres pays et chez d'autres écrivains. 


\section{La Bibliographie :}

\section{I- Corpus}

- NOTHOMB, Amélie,(1999), Stupeur et tremblements, Albin Michel,Paris.

\section{II-Romans consultés :}

- NOTHOMB, Amélie,(1992), Hygiène de l'assassin,: Albin Michel,Paris.

- NOTHOMB, Amélie,(2004), Biographie de la faim, Albin Michel,Paris.

\section{III- Euvres critiques sur Nothomb}

- AMANIEUX, Laureline,(2005), Amélie Nothomb, l'éternelle affamée Albin Michel, Paris.

- DAVID,Michel,(2006),Amèlie Nothomb,le symptôme graphomane, L'Harmattan (collection l'œuvre et la psyché),Paris.

- DA ROCHA, Soares,(2007), la représentation littéraire de la nature chez Amélie Nothomb, Échos écologiques dans ses romans autobiographiques, Editions, le Grand Miroir, Bruxelles.

- JACCOMARD, Hélène,(2004), «La plus grande autobiographie de l'univers. ") L'hyper - autobiographie d'Amélie Nothomb, Éditions de la découverte, Paris.

- NARJOUX,Cécile,(2004),Étude sur Stupeur et tremblements,Ellipses, (collection Résonnances), Paris.

- SUSAN Bainbrigge et JEANETTE den Toonder, dans l'ouvrage collectif: autour d'Amélie Nothomb,(2001), Actes du colloques organisé par l'université d'Edimbourg

- SYLVESTER,Katelyn,(2008),L'ironie de l'impuissance dans "Stupeur et tremblements"une satire de l'entreprise japonaise.Dans CLEF(comment l'esprit vint aux femmes).

IV-Articles parus dans des revues ou des périodiques:

- LECLERE, Marie - Françoise,(2008), Amélie Nothomb l'écriture et la vie in le point.

- RABAUDY Martin (de),(1999), « occupons - nous d'Amélie, l’Express.

\section{V- Ouvrages généraux}

- AMON, Evelyne et BOMATI, Yves,(1995), Vocabulaire du Commentaire du texte, Larousse, Paris.

- FERNANDEZ-ZOILA, Adolfo,(1993), les complexes, France.

- FREUD,Sigmund,(1915),Métapsychologie,Edition:Flammarion, collection: champs classiques.

- FUI,Lee Luck,(2003), Michel Tournier et le détournement de l'autobiographie, Éditions Universitaires de Dijon.

- LAPLANCHE, Jean et PONTALIS, J.B.,(1967), Vocabulaire de la psychanalyse, Presses universitaires de France.

\section{VI-Références électroniques}

- http://membres.multimania.fr/fenrir/nothromb/biographie.htm.

- http://tpe racisme.i france. Com/racisme.htm.

- http//www.toupie.org/dictionnaire/racisme.htm.

- Guerdin, Nicolas, propos recueillis par, http://membres. Lycos. Fr/fenrir/nothomb.htm. 
- $\quad$ http://www.multimania/fenrir/nothomb/Stupeur.htm.

- http://djei76.free.fr/portraits/raciste.html.

- http://djei.free.fr/portraits/sadique.html.

- $\quad$ http://fr.wikipédia.org/wiki/M\%c3\%A9 canisme de d\%3\%A9 fense.

- http://www.kulturica.com/sisyphe.htm.

\section{VII-Dictionnaires}

- $\quad$ AMIEL,Philippe,DU BOURJAL,Hervé,VIENNE,Brigitte,(1989), Dictionnaire du français, Paris.

- ROBERT,Paul,REY,Alain,REY,Josette,MicroRobert,(1986),__ Dictionnaire du français primordial, Debove, Paris. 


\section{عالم العمل فى اليابان}

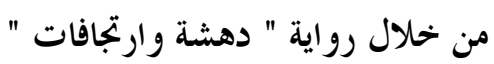

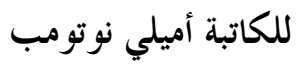

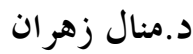

\section{مدرس بقسم اللغة الفرنسية - كلية التربية -جامعة عين شمس}

أميلي نوتومب كاتبة معاصرة استطاعت في فترة وجيزة أن تحتل مكانة كبيرة في عالم الأدب

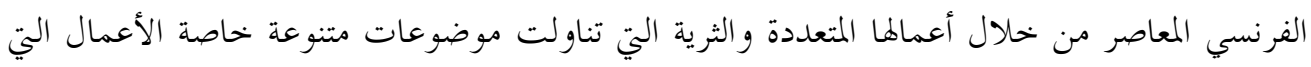
تتعلق بالسيرة الذاتية .

ولدت أميلي نوتومب في اليابان سنة 197 و حيث قضت الخمس سنوات الأولى من عمرها

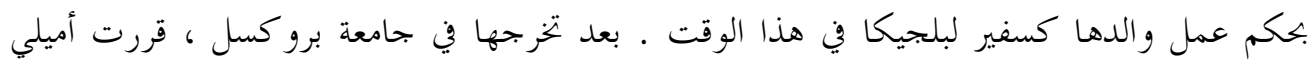

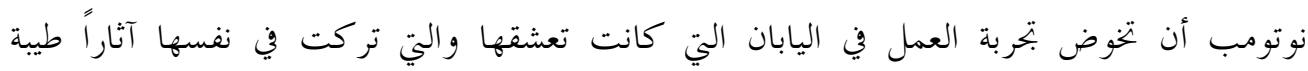

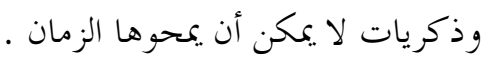

وبالفعل استطاعت أميلي أن تحصل على عقد عمل لمدة عام عام في إحدي الشركات الكبري في

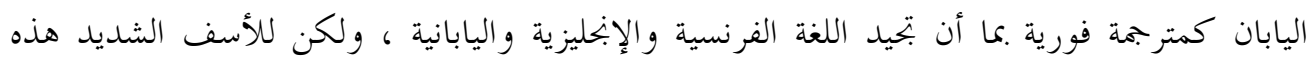

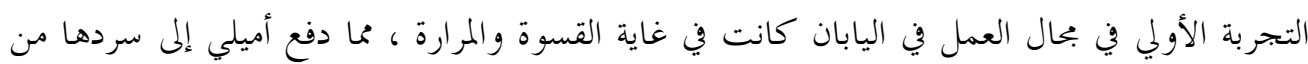

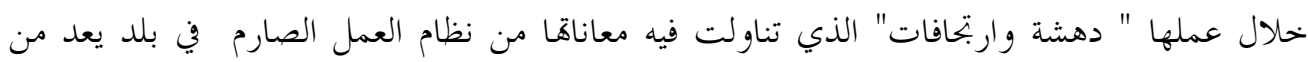
البلاد المتحضرة و المتقدمة كاليابان.

وفي هذا السياق يتناول البحث النقاط التالية:

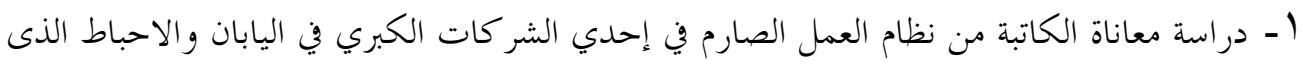

$$
\text { تعرضت له. }
$$

Y- الآليات التي لجأت إليها الكاتبة لكي تستطيع أن تتحمل هذه التجربة القاسية بما فيها من إهانات

$$
\text { واحتقار وإذلال من جهة الرؤساء. }
$$




\section{Les références:}

(1) Née en 1967 à kobe, au Japon, Amélie Nothomb est fille de l'ambassadeur de Belgique à Rome, petite-nièce de l'homme politique Charles - Ferdinand Nothomb. [...]. Amélie Nothomb passe ses cinq premières années au Japon, dont elle restera profondément marquée, allant jusqu'à parler couramment japonais et à devenir interprète. Mais son expérience d'expatriée ne s'arrête pas là puisqu'elle vivra successivement en Chine, à New York, au Bengladesh, en Birmanie et au Laos, avant de débarquer à dix-sept ans sur le sol de Belgique, berceau de sa famille où elle entame une licence en philologie romane à l'université libre de Bruxelles. [...] Amélie Nothomb publie en 1992 son roman

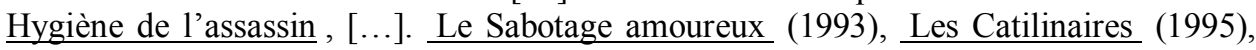
Péplum (1996),

Attentat (1997), Mercure (1998), Stupeur et tremblements (1999, Grand Prix du roman de l'Académie française).(Narjoux, 2004:5-6).

(2) «Les Samouraïs appartenaient à la classe des guerriers. Dépendant de la noblesse, ils devaient obéissance à leur suzerain, et à un code de l'honneur très stricte, le Bushido, la voie du guerrier. »(Amanieux,2005:46-47).

(3) La mythologie grecque raconte que lorsque Thésée, roi d'Athènes, tua Sisyphe au combat au cours d'une guerre qui opposa les deux villes voisines, Athènes et Corynthe, Sisyphe fut envoyé aux Enfers, où il était condamné à rouler indéfiniment une énorme roche ronde jusqu'en haut d'une montagne. Parvenue au sommet, la roche sous l'effet de la gravité, redescendait juqu'au pied de la montagne, et Sisyphe devait recommencer sa harassante tâche.

Ce supplice éveille des échos dans notre monde moderne, il semble que nous tous soyons condamnés à accomplir des tâches et à les reproduire indéfiniment, pour le seul besoin d'accomplir ces tâches. http://www.kulturica. com/sisyphe.htm. 